\title{
Fluorometric Method for the Determination of Gemifloxacin Mesylate in Bulk and Pharmaceutical Formulations Using $\mathrm{Tb}^{3+}$ lons in the Presence of Hexamine
}

\author{
Sharifah Ghaythan Dbsan Alharthi, ${ }^{1,2}$, Ayman Abdelaziz Osman ${ }^{1,3}$, Salma Ali Altamimi ${ }^{2}$, \\ Fatma Elzahraa Ali ${ }^{2}$ \\ ${ }^{1}$ Department of Chemistry, College of Science and Home Economic, Bisha University, Bisha, Saudi Arabia \\ ${ }^{2}$ Department of Chemistry, College of Science, King Saud University, Riyadh, Saudi Arabia \\ ${ }^{3}$ Departmen of Chemistry, College of Science and Education, University of West Kurdofan, EL Nuhud, Sudan
}

Email address:

Sho8896@hotmail.com (S. G. D. Alharthi)

\section{To cite this article:}

Sharifah Ghaythan Dbsan Alharthi, Ayman Abdelaziz Osman, Salma Ali Altamimi, Fatma Elzahraa Ali. Fluorometric Method for the Determination of Gemifloxacin Mesylate in Bulk and Pharmaceutical Formulations Using $\mathrm{Tb}^{3+}$ Ions in the Presence of Hexamine. Science Journal of Analytical Chemistry. Vol. 5, No. 1, 2017, pp. 1-7. doi: 10.11648/j.sjac.20170501.11

Received: December 31, 2016; Accepted: January 12, 2017; Published: February 6, 2017

\begin{abstract}
A simple and highly sensitive method for the determination of Gemifloxacin Mesylate in bulk drug and pharmaceutical formulations. The method is based on the reaction of Gemifloxacin Mesylate with $\mathrm{Tb}^{3+}$ in the presence of hexamine at $\mathrm{pH} 7.2$. The fluorescence was measured at $545 \mathrm{~nm}$ after excitation at $271 \mathrm{~nm}$. The calibration graph was linear over the range $0.05-1.3 \mu \mathrm{g} \mathrm{mL}$, with minimum quantification limit (LOQ) of $0.024 \mu \mathrm{g} \mathrm{mL}$ and minimum limit of detection (LOD) of $7.65 \times 10^{-3} \mu \mathrm{g} \mathrm{mL}$. The proposed method was successfully applied for the determination of this drug in its dosage forms.
\end{abstract}

Keywords: Gemifloxacin Mesylate, Spectrofluorometry, Terbium(III), Hexamine, Ternary Complex

\section{Introduction}

Gemifloxacin Mesylate (GEM) is a broad-spectrum fluoroquinolone antibacterial agent. Its bactericidal activity depends on inhibition of DNA synthesis. This mode of action involves dual targeting of two bacterial enzymes: DNA gyrase and topoisomerase IV, which are essential for bacterial DNA replication and transcription [1]. Chemically, it is designated as ( \pm )-7-[3-(aminomethyl)-4-(methoxyimino)-1-pyrrolidinyl]-1-c yclopropyl-6-fluoro-1,4-dihydro-4-oxo-1,8-naphthyridine-3-ca rboxylicacidmethanesulfonate $[1,2]$ (Figure 1).

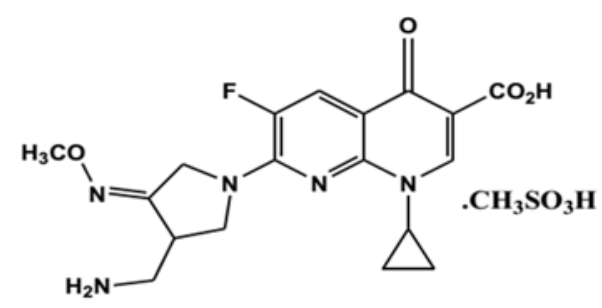

Figure 1. Chemical Structures of Gemifloxacin Mesylate.
GEM is not official in any pharmacopoeia. The literature survey revealed several reported analytical approaches for its determination in pharmaceutical dosage forms and in biological fluids. Various spectrophotometric [3 - 11] and spectrofluorimetric $[12,13]$ methods were described. Chromatographic methods were also reported and include capillary electrophoresis [14], HPTLC [15] and HPLC [16].

The present paper describes a specific and highly sensitive method for the determination of Gemifloxacin Mesylate that can be adopted for its determination in tablets. The method is based on the reaction of Gemifloxacin Mesylate with $\mathrm{Tb}^{3+}$ in the presence of hexamine at $\mathrm{pH}$ 7.2.

\section{Materials and Methods}

\subsection{Materials and Reagents}

All chemicals used were of analytical reagent grade, and the solvents were of spectroscopic grade. Pure grade Gemifloxacin Mesylate and its tablets (Factive ${ }^{\circledR} 320$ $\mathrm{mg} /$ tablet) were supplied from Tabuk pharmaceutical. MFG. 


\section{CO., Saudi Arabia.}

Terbium (III) chloride hexahydrate solution, An aqueous solution of $1 \times 10^{-3} \mathrm{M}$ Terbium (III) chloride hexahydrate $\left(\mathrm{TbCl}_{3} .6 \mathrm{H}_{2} \mathrm{O}\right.$, 99.9\%; Sigma, ALdrich, Germany), was prepared by dissolving $0.037 \mathrm{~g}$ in $100 \mathrm{~mL}$ of distilled water. Hexamine solution, An aqueous solution of $1 \%(\mathrm{~W} / \mathrm{V})$ hexamine (Sigma, ALdrich, Germany), was prepared and its $\mathrm{pH}$ was adjusted to 7.2 with $1 \mathrm{M} \mathrm{HCL}$.

\subsection{Instrument}

The fluorescence intensity was measured on a Perkin-Elmer model RF-5301PC Spectrofluorphotometer (SHIMADZU), equipped a $150 \mathrm{~W}$ xenon arc lamp, grating excitation and emission monochromators and a Perkin-Elmer recorder. Slit widths for excitation and emission monochromators were set at 3.0 and $3.0 \mathrm{~nm}$, respectively. A $1 \mathrm{~cm}$ quartz cells was used for all measurements. $\mathrm{pH}$ was measured on a HANNA $\mathrm{pH}$ meter (Romania).

\subsection{Preparation of Standard Solution}

A stock solution containing $10.0 \mathrm{mg} / \mathrm{mL}$ of Gemifloxacin Mesylate was prepared in distilled water. This solution was found to be stable for two week without alteration when kept in the refrigerator. Working standard solution were prepared from stock solution further dilution with distilled water to cover the working range of $0.05-1.3 \mu \mathrm{g} / \mathrm{mL}$.

\subsection{Procedures}

\subsubsection{Construction of the Metal Complexes Calibration Graphs}

Transfer $2.0 \mathrm{ml}$ of $\mathrm{TbCl}_{3} \cdot 6 \mathrm{H}_{2} \mathrm{O}\left(1 \times 10^{-3} \mathrm{M}\right)$ into a series of
$10 \mathrm{~mL}$ standard flasks. Add Gemifloxacin Mesylate covering the working range $(0.05-1.3 \mu \mathrm{g} / \mathrm{mL})$ then add $2 \pm 0.1 \mathrm{ml}$ of hexamine solution of $\mathrm{pH} 7.2 \pm 0.2$. Complete to volume with distilled water. Measure the fluorescence intensity at $545 \mathrm{~nm}$ using $271 \mathrm{~nm}$ as an excitation wavelength. Plot the concentration versus the fluorescence Intensity (FI) to obtain the standard calibration graph. Alternatively one could calculate the linear regression equation.

\subsubsection{Application of the Proposed Method to the Analysis of Gemifloxacin Mesylate in Its Tablets}

An accurately weighed amount of ten powdered tablets equivalent to $10.0 \mathrm{mg}$ of Gemifloxacin Mesylate was transferred into a $100 \mathrm{~m} \mathrm{~L}$ volumetric flask and completed to volume with distilled water. The flask with its contents was sonicated for $30 \mathrm{~min}$ and then filtered. The above procedure was followed. The nominal content was calculated either from the previously plotted calibration graph or using the corresponding regression equation.

\section{Results and Discussion}

The Gemifloxacin Mesylate- $\mathrm{Tb}^{3+}$-hexamine ternary complex (GFX-Tb(III)- $\left.\mathrm{N}_{4}\left(\mathrm{CH}_{2}\right)_{6}\right)$ was found to exhibit intense fluorescence at $545 \mathrm{~nm}$ after excitation at $271 \mathrm{~nm}$ (Figure. 2). The fluorophore was formed instantaneously and remained stable for more than $1 \mathrm{~h}$. Compared to the native fluorescence of Gemifloxacin Mesylate, the product is 2.5 times more intense (Figure. 3).

Moreover, the effect of different concentration of Gemifloxacin Mesylate- $\mathrm{Tb}^{3+}$-hexamine ternary complex on the fluorescence intensity was studied (Figure 4).
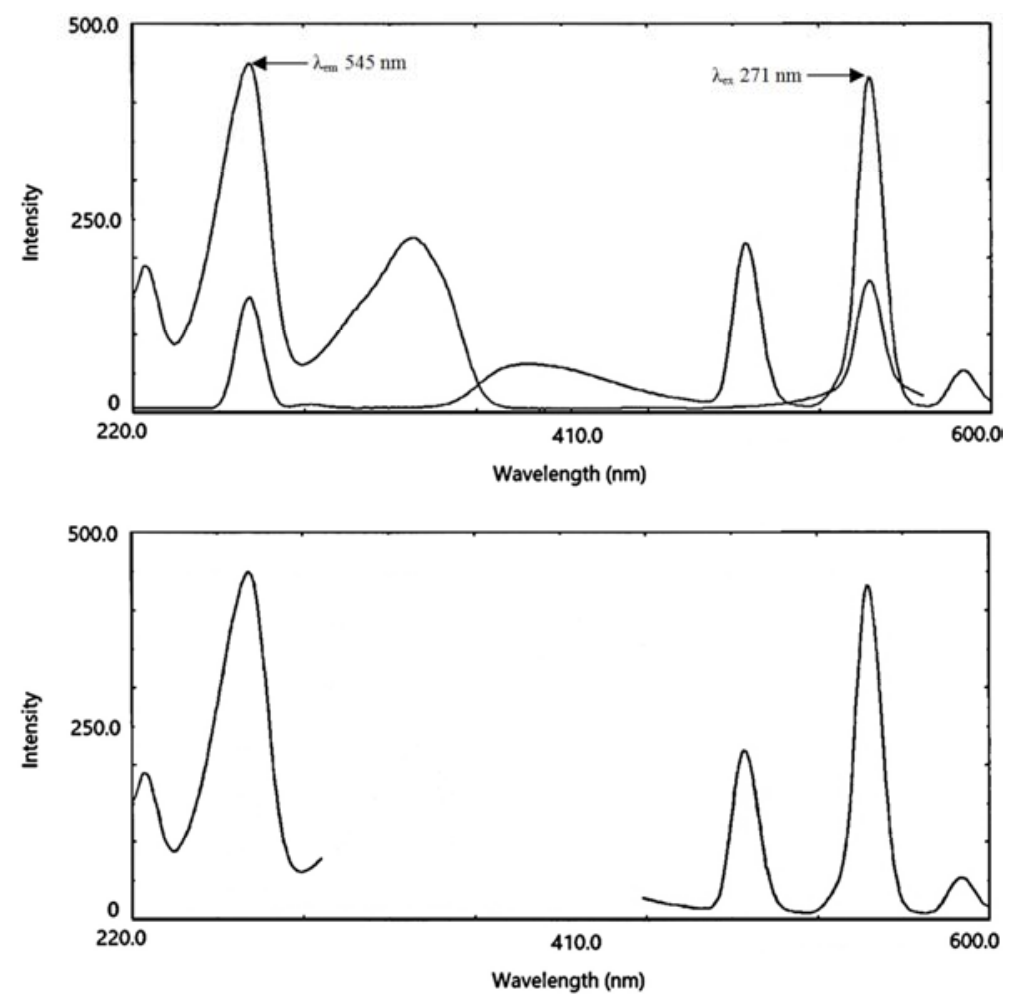

Figure 2. Fluorescence spectra of Gemifloxacin Mesylate-Tb ${ }^{3+}$-hexamine ternary complex (Excitation spectra 261nm)(Emission spectra $545 \mathrm{~nm}$ ). 


\subsection{Optimization of the Reaction Condition}

The factors affecting the reaction conditions were carefully studied and optimized. Such factors were changed individually while the others were kept constant. These factors included reagents concentration, nature of the solvent, reaction time and stability.

\subsubsection{Effect of $\mathrm{pH}$ and Buffer Solution}

It was found that upon using $1 \%(\mathrm{~W} / \mathrm{V})$ hexamine solution covering the $\mathrm{pH}$ range from 5 to 10 , maximum fluorescence intensity was obtained at and above $\mathrm{pH}$ 7.0. Higher $\mathrm{pH}$ values did not affect the fluorescence intensity (Figure 5). Therefore, $\mathrm{pH} 7.0 \pm 0.2$ was recommended for the determination. At the same time, some buffer was studied as follows: Tris- $\mathrm{HCl}$, Borate buffer, phosphate buffer, acetate buffer. It was not effected on the fluorescence intensity; the highest fluorescence intensity was obtained in hexamine.

\subsubsection{Effect of Hexamine Concentration}

The effect of hexamine concentration on the fluorescence intensity was studied using different volumes $(0.1-4.0 \mathrm{~mL})$ of hexamine. Figure 6 show the maximum fluorescence intensity was attained using $1.5 \mathrm{~mL}$, after which hexamine has no effect on the fluorescence intensity. Thus $2 \mathrm{~mL}$ of hexamine was used for further studies.

\subsubsection{Effect of Terbium Concentration}

The effect of Terbium (III) chloride hexahydrate concentration on the fluorescence intensity was studied using different volumes $(0.1-4.0 \mathrm{~mL})$ of $\mathrm{TbCl}_{3} \cdot 6 \mathrm{H}_{2} \mathrm{O}$. Figure 7 show the maximum fluorescence intensity was attained using $1.0 \mathrm{~mL}$, after which $\mathrm{TbCl}_{3} \cdot 6 \mathrm{H}_{2} \mathrm{O}$ has no effect on the fluorescence intensity. Thus $2 \mathrm{~mL}$ of $1 \times 10^{-3} \mathrm{M} \mathrm{TbCl}_{3} \cdot 6 \mathrm{H}_{2} \mathrm{O}$ was used for further studies.

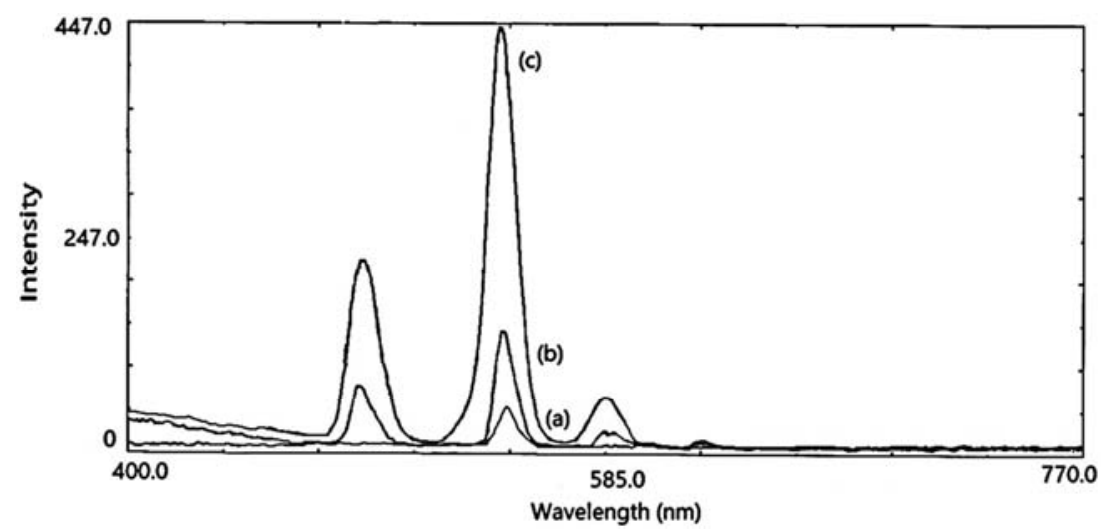

Figure 3. Fluorescence emission spectra of: (a) Blank, (b) Gemifloxacin Mesylate and hexamine, (d) Gemifloxacin Mesylate-Tb ${ }^{3+}$-hexamine ternary complex.

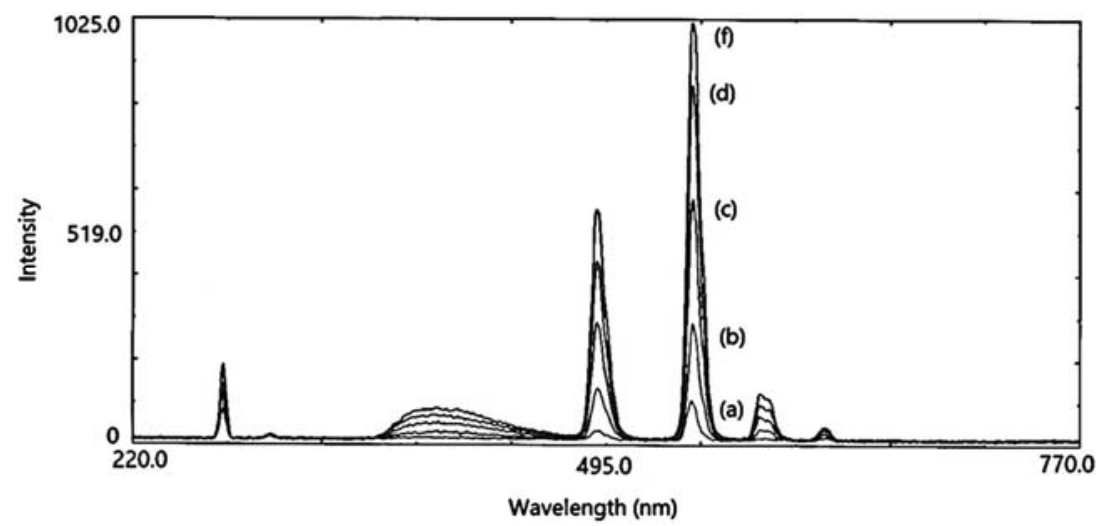

Figure 4. Fluorescence emission spectra of Gemifloxacin Mesylate-Tb ${ }^{3+}$-hexamine ternary complex.(a) $0.05 \mu \mathrm{g} / \mathrm{mL}$, (b) $0.3 \mu \mathrm{g} / \mathrm{mL}$, (c) $0.7 \mu \mathrm{g} / \mathrm{mL}$, (d) $1.1 \mu \mathrm{g} / \mathrm{m}$, (f) $1.3 \mu \mathrm{g} / \mathrm{mL}$.

\subsubsection{Effect of Reagent Addition Order}

The effect of the order of reagent addition on the fluorescence intensity was also examined. The results indicated that an addition order of $\mathrm{Tb}^{3+}$, GFX and $\mathrm{N}_{4}\left(\mathrm{CH}_{2}\right)_{6}$ colloidal solution offered the maximum intensity which was chosen for this study.

\subsubsection{Stability Test}

The experiments indicated that the fluorescence intensity of the system reached maximum in 30 min after all the reagents had been added and remained stable for more than $1 \mathrm{~h}$. 


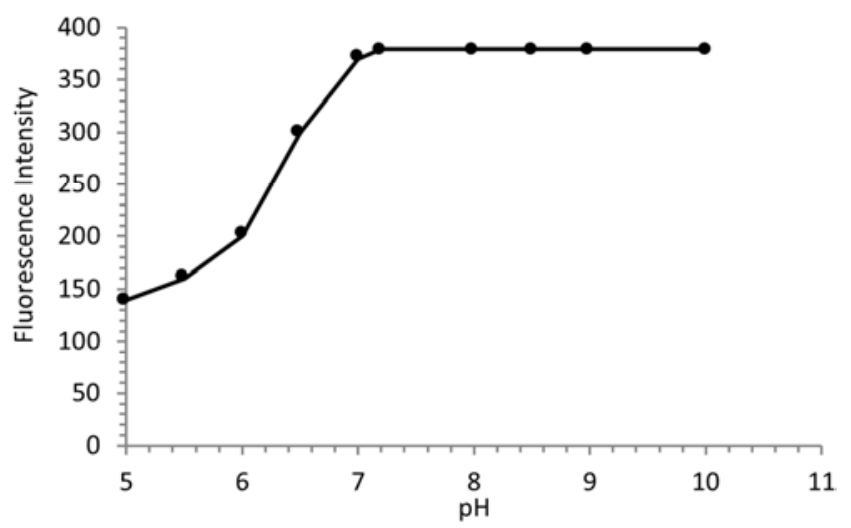

Figure 5. Effect of $p$ H on the fluorescence product of gemifloxacin mesylate $(0.5 \mu \mathrm{g} / \mathrm{ml})$ and $T b^{3+}$.

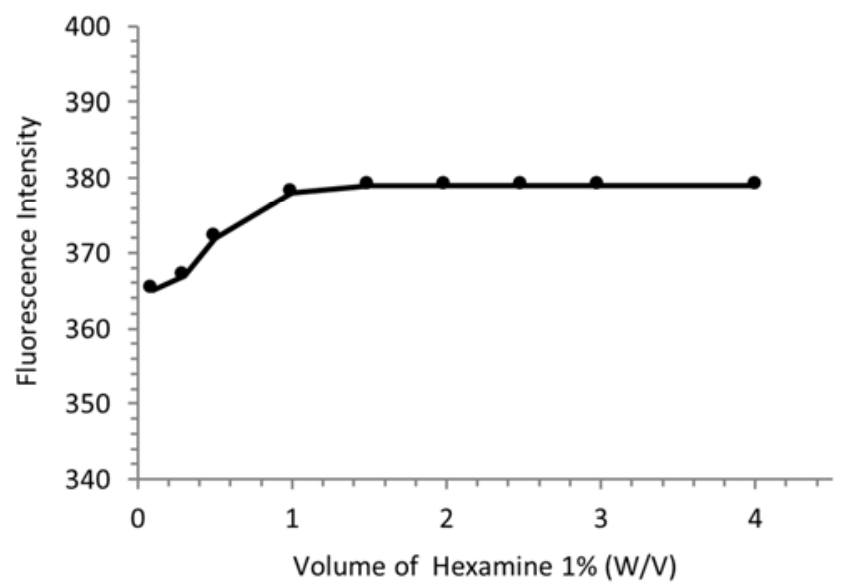

Figure 6. Effect of volume of $1 \%(W / V)$ of hexamine $(P H=7.2)$ on its reaction with gemifloxacin mesylate $(0.5 \mu \mathrm{g} / \mathrm{ml})$ and $\mathrm{Tb}^{3+}$.

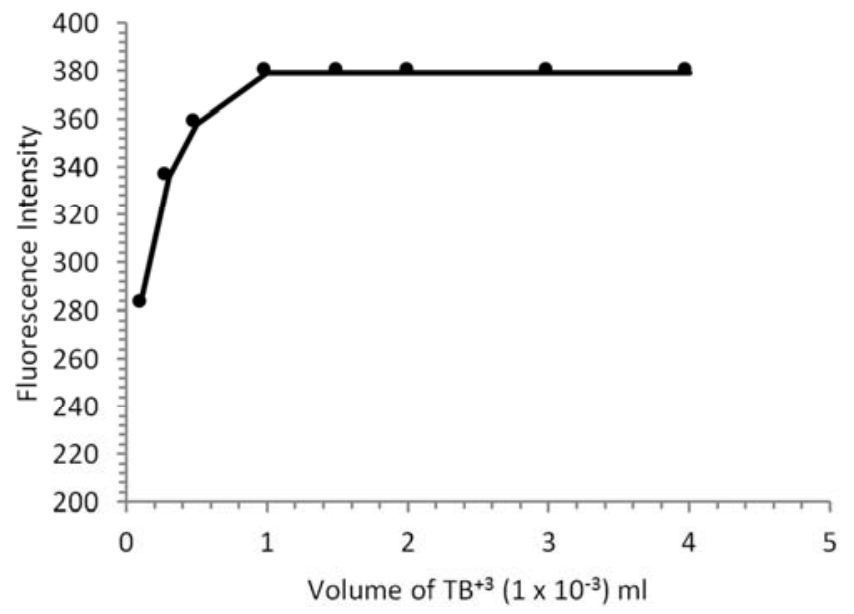

Figure 7. Effect of volum of $\left(1 \times 10^{-3}\right) \mathrm{Tb}^{3+}$ on its reaction of gemifloxacin mesylate $(0.5 \mu \mathrm{g} / \mathrm{ml})$ and hexamine.

\subsection{Stoichiometry and Reaction Mechanism}

The stoichiometry of the reaction was studied by the molar ratio method [17] and was found to be 1: $3\left[\mathrm{~Tb}^{3+}-\right.$ Gemifloxacin Mesylate] as shown in Figure 8. The reaction pathway was postulated to proceed as shown in Figure 9.

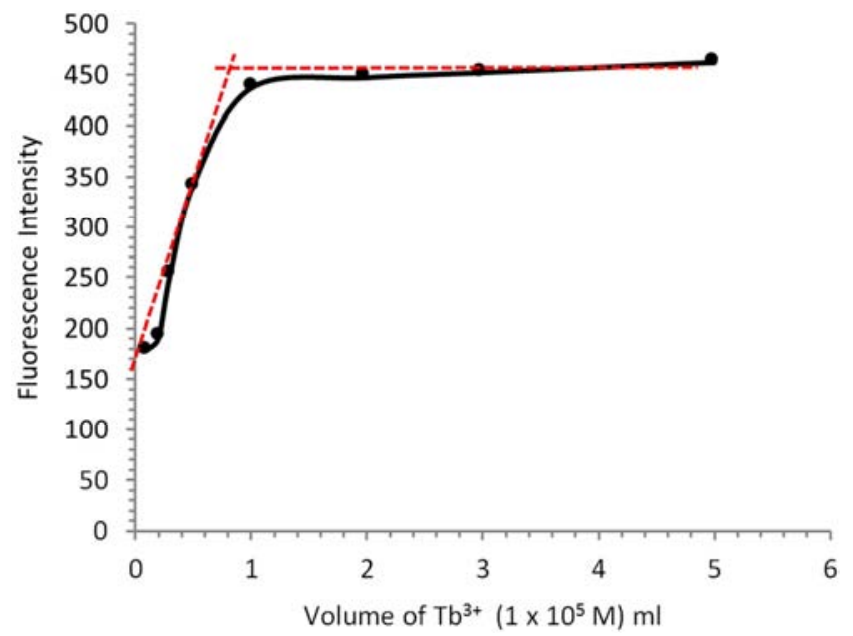

Figure 8. The determination of Molar Reactivity of gemifloxacin mesylate (3 $m L$ of $1 \times 10^{-5}$ ) complex at $p H 7.2$.

\subsection{Validation}

\subsubsection{Linearity and Range}

After optimization the reaction conditions, calibration graph was constructed by plotting the fluorescence intensity $v s$ Gemifloxacin Mesylate concentration. A straight liner was obtained over the concentration range $0.05-1.3 \mu \mathrm{g} / \mathrm{m} \mathrm{L}$ (Figure. 10).

Linear regression analysis of the data using the method of least squares [18] gave a high value of the correlation coefficient (r), small values of standard deviation of intercept $\left(\mathrm{S}_{\mathrm{a}}\right)$, and standard deviation of slope $\left(\mathrm{S}_{\mathrm{b}}\right)$. These data proved the linearity of the calibration graph. Table 1 shows the performance data for the determination of Gemifloxacin Mesylate with $\mathrm{Tb}^{3+}$ in the presence of hexamine at $\mathrm{pH}$ 7.2.

\subsubsection{Accuracy and Precision}

To prove the accuracy of the proposed methods, the results of the assay of Gemifloxacin Mesylate in pure form were compared with those of the published spectrophotometric method [8]. Statistical analysis of the results obtained by the proposed and published methods using Student's $t$-test and variance ratio $F$-test, showed no significant difference between them regarding accuracy and precision, respectively (Table 2) [18].

Intraday and interday precisions were assessed using three concentration and three replicates of each concentration. The standard deviations were found to be very small indication reasonable, repeatability and intermediate precision of the proposed methods (Table 3 ). 


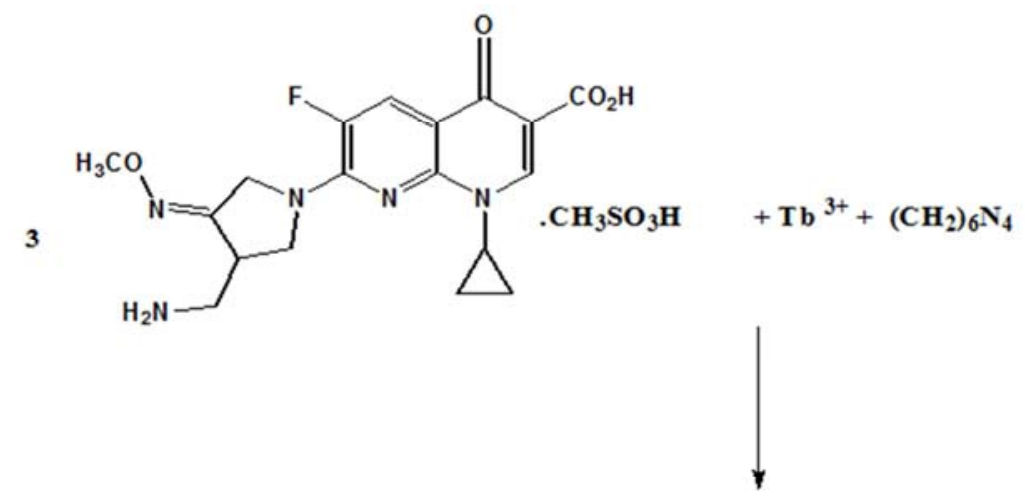<smiles>CO/N=C1\CN(c2nc3c(cc2F)c(=O)c(C(=O)O)cn3C2CC2)CC1CN</smiles><smiles>CCOC(=O)c1cn(C2CC2)c2nc(N3C/C(=N\OC)C(CN)C3)c(F)cc2c1=O</smiles><smiles>CO/N=C1\CN(c2nc3c(cc2F)c(=O)c(C(=O)OC)cn3C2CC2)CC1CN</smiles>

$+3 \mathbf{H}^{+}$

Figure 9. The Proposed pathway for the reaction of Gemifloxacin Mesylate with $\mathrm{Tb}^{3+}$ in the presence of hexamine.

\subsubsection{Selectivity}

The selectivity of the optimized procedures for the assay of Gemifloxacin Mesylate was excipients present in Factive ${ }^{\circledR}$ tablets, e.g. crospovidone, hydroxypropyl methylcellulose, magnesium stearate, microcrystalline cellulose, polyethylene glycol, povidone, and titanium dioxide [19]. It was found that there is no significant interference from excipients. Accordingly, the proposed procedure can be considered as a selective method.

\subsubsection{Limited of Detection (LOD) and Limited of Quantitation (LOQ)}

LOD and LOQ were determined according to the ICH [20] guidelines, LOD was determined by establishing the minimum level at which the analyte can reliably be detected, using the relation $3.3\left(\mathrm{~S}_{\mathrm{a}}\right) / \mathrm{b}$ [20], LOQ is the lowest amount of analyte in a sample that can be determined with acceptable precision and accuracy under the stated experimental conditions, using the relation $10\left(\mathrm{~S}_{\mathrm{b}}\right) / \mathrm{b}$ [20]. The results are illustrated in Table 1.

\subsubsection{Ruggedness}

To examine the ruggedness of procedures, the interday precisions were evaluated as shown in Table 3 . The precision of the proposed method was found to be fairly high, as indicated by the low values of S.D.

\subsubsection{Robustness}

The robustness of the methods was demonstrated by the constancy of the fluorescence intensity with minor changes in the experimental parameters such as $2.0 \pm 0.2 \mathrm{~mL}$ of $1 \times 10^{-3} \mathrm{M}$ 
$\mathrm{TbCl}_{3} \cdot 6 \mathrm{H}_{2} \mathrm{O}$ and $2.0 \pm 0.2 \mathrm{~mL}$ of $1 \%(\mathrm{~W} / \mathrm{V})$ hexamine $(\mathrm{pH}=7.2)$ These minor changes that may take place during the experimental operation did not affect the fluorescence intensity.

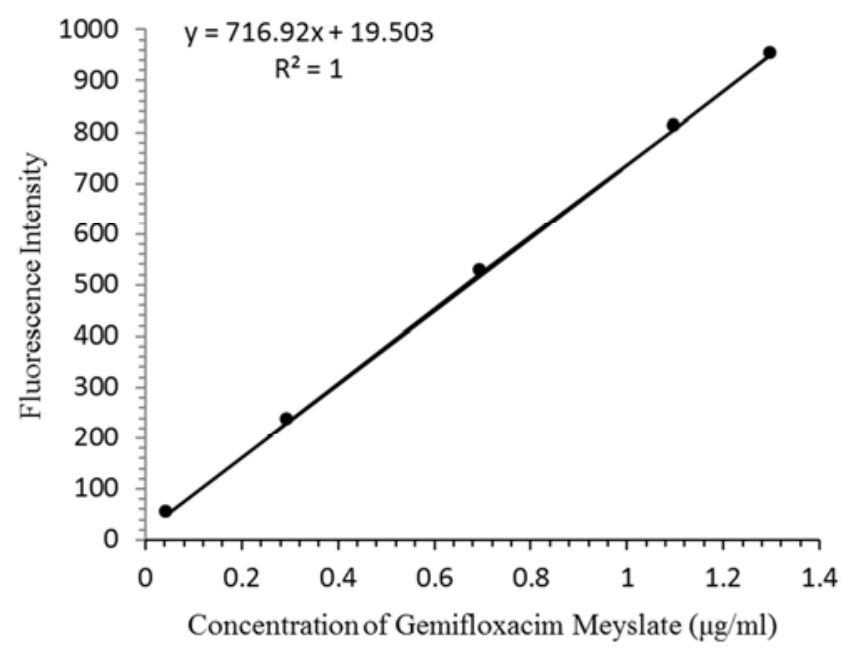

Figure 10. Calibration curve for the determination of gemifloxacin mesylate with $\mathrm{Tb}^{3+}$ in the presence of hexamine at $545 \mathrm{~nm}$ after excitation at $271 \mathrm{~nm}$.

Table 1. Analytical performance data for the fluorometric determination of Gemifloxacin Mesylate with $\mathrm{Tb}^{3+}$ in the presence of hexamine.

\begin{tabular}{ll}
\hline parameter & value \\
\hline Wavelength $\left[\lambda_{\text {ex. }} / \lambda_{\text {em }}\right](\mathrm{nm})$ & $271 / 545$ \\
Linearity range $(\mu \mathrm{g} / \mathrm{ml})$ & $0.05-1.3$ \\
Intercept & 19.503 \\
slope & 716.923 \\
Correlation coefficient $(\mathrm{r})$ & 0.9999 \\
S.D. of Intercept $\left(\mathrm{S}_{\mathrm{a}}\right)$ & 1.663 \\
S.D. of slope $\left(\mathrm{S}_{\mathrm{b}}\right)$ & 1.993 \\
S.D. & 0.702 \\
Relative standard deviation $\% \mathrm{RSD}$ & 0.700 \\
SE & 0.313 \\
Limit of detection LOD $(\mu \mathrm{g} / \mathrm{ml})$ & $7.65 \times 10^{-3}$ \\
Limit of quantitation LOQ $(\mu \mathrm{g} / \mathrm{ml})$ & 0.024 \\
Molar ratio $($ drug/reagent $)$ & $1: 03$ \\
\hline
\end{tabular}

Table 2. Analytical of Gemifloxacin Mesylate in pure from by the proposed fluorometric method using $\mathrm{Tb}^{3+}$ in the presence of hexamine and published methods.

\begin{tabular}{llll}
\hline $\begin{array}{l}\text { Concentration } \\
\text { found }(\boldsymbol{\mu g} / \mathbf{m L})\end{array}$ & $\begin{array}{l}\text { Concentration } \\
\text { taken }(\boldsymbol{\mu g} / \mathbf{m L})\end{array}$ & $\begin{array}{l}\mathbf{( \% )}^{\text {Published }} \\
\text { method }^{(8)}\end{array}$ & $\begin{array}{l}\text { Proposed } \\
\text { method }\end{array}$ \\
\hline 98.00 & 98.30 & 0.049 & 0.05 \\
99.75 & 100.05 & 0.300 & 0.3 \\
99.91 & 100.607 & 0.704 & 0.7 \\
99.60 & 99.83 & 1.098 & 1.1 \\
99.82 & 99.94 & 1.299 & 1.3 \\
Mean \pm S. D & - & $99.74 \pm 0.86$ & $99.41 \pm 0.79$ \\
Student's $t$-value & - & 0.638 & - \\
Variance ratio $F$-test & - & $(2.306)^{\mathrm{b}}$ & - \\
\hline
\end{tabular}

${ }^{\mathrm{a}}$ Each result is the average of three separation determinations.

${ }^{b}$ the figures between parentheses are the tabulated values of $t$ and $F$ at $\mathrm{P}=0.05$ [18].
Table 3. Precision data for the determination of Gemifloxacin Mesylate by the proposed fluorometric method using $\mathrm{Tb}^{3+}$ in the presence of hexamine.

\begin{tabular}{lllll}
\hline \multirow{2}{*}{ Parameter } & & \multicolumn{3}{l}{ gemifloxacin mesylate $(\boldsymbol{\mu g} / \mathbf{m L})$} \\
\cline { 3 - 5 } & & $\mathbf{0 . 0 5}$ & $\mathbf{0 . 7 0}$ & $\mathbf{1 . 3 0}$ \\
\hline \multirow{3}{*}{ Intraday } & & 98.30 & 100.05 & 100.10 \\
& & 98.85 & 100.90 & 99.04 \\
& & 99.19 & 100.22 & 100.58 \\
& Mean & 98.78 & 100.39 & 99.90 \\
& S.D. & 0.45 & 0.45 & 0.78 \\
& S(mean) ${ }^{\mathrm{b}}$ & 0.25 & 0.25 & 0.45 \\
& & 98.30 & 101.00 & 100.10 \\
& & 99.90 & 100.00 & 98.51 \\
& & 98.53 & 99.63 & 99.74 \\
& & 98.91 & 100.21 & 99.45 \\
& & 0.86 & 0.71 & 0.83 \\
& Mean & 0.49 & 0.41 & 0.48 \\
\hline
\end{tabular}

${ }^{a}$ Each result is the average of three separation determinations.

${ }^{\mathrm{b}}$ Calculated as $(\mathrm{S} . \mathrm{D} / \sqrt{ } \mathrm{N})$

\subsection{Application on the Analysis of Dosage Form}

In order to evaluate the analytical usefulness of the proposed Spectrofluorphotomete method, Gemifloxacin Mesylate was determined in its tablets. The recoveries of the different concentration of Gemifloxacin Mesylate were based on the average of three replicate determinations. The results obtained were in good agreement with those obtained by the published spectrophotometric method [8] (Table 4). Statistical analysis [18] of the results obtained by the proposed and the comparison methods shows no significant difference between the two methods as regards to accuracy ( $t$-test) and precision $(F$-test).

Table 4. Analytical of Gemifloxacin Mesylate in tablets from by the proposed fluorometric method using $\mathrm{Tb}^{3+}$ in the presence of hexamine and published methods.

\begin{tabular}{|c|c|c|c|}
\hline \multirow[b]{2}{*}{ Preparations } & \multirow[b]{2}{*}{$\begin{array}{l}\text { Concentration } \\
\text { taken }(\mu \mathrm{g} / \mathrm{mL})\end{array}$} & \multicolumn{2}{|l|}{$(\%)$ Found $^{\mathrm{a}}$} \\
\hline & & $\begin{array}{l}\text { Proposed } \\
\text { method }\end{array}$ & $\begin{array}{l}\text { Published } \\
\text { method }\end{array}$ \\
\hline \multirow{5}{*}{ 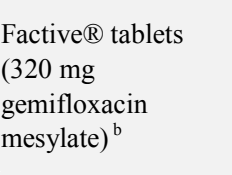 } & 0.05 & 98.43 & 98.29 \\
\hline & 0.3 & 100.21 & 99.70 \\
\hline & 0.7 & 101.30 & 100.39 \\
\hline & 1.1 & 100.01 & 99.09 \\
\hline & 1.3 & 99.82 & 101.22 \\
\hline Mean \pm S.D. & & $99.95 \pm 1.02$ & $99.73 \pm 1.13$ \\
\hline Student's $t$-value & & $0.327(2.306)^{\mathrm{c}}$ & - \\
\hline Variance ratio $F$-test & & $1.227(6.39)^{\mathrm{c}}$ & - \\
\hline
\end{tabular}

${ }^{a}$ Each result is the average of three separation determinations.

${ }^{b}$ products of Tabuk Pharma. MFG. CO., Saudi Arabia. ${ }^{c}$ the figures between parentheses are the tabulated values of $t$ and $F$ at $\mathrm{P}=0.05$ [17].

\section{Conclusion}

The proposed fluorometric method could be successfully used for the determination of Gemifloxacin Mesylate in the pharmaceutical formulation. The proposed procedure is a simple, sensitive, reliable, and rapid. It could be regarded as a useful technique for the routine quality control of pharmaceutical formulations with a relatively inexpensive instrumentation. In addition, the proposed method is very suitable to be applied in content uniformity testing. 


\section{References}

[1] T. L. Lemke, D. A. Williams, V. F. Roche and S. W. Zito. (2008), Foye's Principles of Medicinal Chemistry, $6^{\text {th }}$ ed., Wolters Kluwer, Lippincott Williams \& Wilkins, New York.

[2] M. J. O’Neil, P. E. Heckelman, C. B. Koch, K. J. Roman, C. M. Kenny and M. R. D'Arecca. (2006). The Merck Index, An Encyclopedia of Chemicals, Drugs and Biologicals, $14^{\text {th }}$ ed., Merck Research Laboratories Division of Merck \& Co., Inc., Whitehouse Station (NJ).

[3] B. A. Moussa, M. A. Mahrouse, M. A. Hassan and M. G. Fawzy. (2013). Stability indicating spectrophotometric and TLC densitometric methods for the determination of gemifloxacin mesylate in tablet form, Anal. Chem. Indian J. 12: 165-176.

[4] C. S. Paim, F. Fuhr, M. Steppe, E. Schapoval and S. Eva. (2012) Gemifloxacin mesylate: UV spectrophotometric method for quantitative determination using experimental design for robustness, Quimica Nova. 35: 193-197.

[5] R. El-Bagary, N. F. Abo-Talib and M. B. N. Eldin. (2011). Validated stability indicating assay of gemifloxacin by different chromatographic and spectrophotometric methods of analysis, J. Chem. Pharm. Res. 3: 562-570.

[6] S. S. Panda, B. V. V. Ravi Kumar, K. S. Rao, V. R. Kumar and D. Patanaik. (2011). Difference spectrophotometric determination of gemifloxacin mesylate in tablet formulation, Asian J. Biochem. Pharm. Res. 1: 442-447.

[7] K. B. C. Sekhar, D. Madhuri and N. Devanna. (2010). Direct and derivative spectrophotometric determination of gemifloxacin mesylate via metal chelate, Acta Cienc. Indica, Ser. Chem. 36: 165- 171.

[8] R. Rote Ambadas and S. P. Pingle. (2010). Validated UV-spectrophotometric methods for determination of gemifloxacin mesylate in pharmaceutical tablet dosage forms, E-J. Chem. 7: S344-S348.

[9] D. Madhuri, K. B. Chandrasekhar, N. Devanna and G. Somasekhar. (2010) Direct and derivative spectrophotometric determination of gemifloxacin mesylate in pure form and pharmaceutical preparations using $\mathrm{p}$ acceptors, Int. J. Pharm. Sci. Res. 1:222-230.

[10] Z. Y. Al Shoaibi and A. A. Gouda. (2010). Spectrophotometric methods for the determination of gemifloxacin mesylate in pure form and pharmaceutical formulations, Anal. Chem: Indian J. 9: 129-136.

[11] M. V. Krishna and D. G. Sankar. (2008). Utility of s and p-acceptors for the spectrophotometric determination of gemifloxacin mesylate in pharmaceutical formulations, E-J. Chem. 5: 493-498.

[12] S. E. K. Tekkeli and A. Önal. (2011). Spectrofluorimetric methods for the determination of gemifloxacin in tablets and spiked plasma samples, J. Fluoresc. 21: 1001-1007.

[13] N. F. Youssef and L. I. Bebawy. (2006). Spectrofluorometric methods for the determination of gemifloxacin mesylate and cefamandole nafate in bulk powder and pharmaceutical preparations, Bull. Fac. Pharm. Cairo Univ. 44: 215-227.

[14] A. A. Elbashir, B. A. Saad, S. M. Abdussalam, K. M. M. Al-Azzam and H. Y. Aboul-Enein. (2008). Validated stability indicating assay of gemifloxacin and lomefloxacin in tablet formulations by capillary electrophoresis, J. Liq. Chromatogr. Rel. Tech. 31: 1465-1477.

[15] A. R. Rote and S. P. Pingle. (2009). Reversed phase-HPLC and HPTLC methods for determination of gemifloxacin mesylate in human plasma, J. Chromatogr. B 877: 3719-3723.

[16] D. Nagavalli, G. Abirami and S. K. Kumar (2011). Validated HPLC method for the simultaneous estimation of gemifloxacin mesylate and ambroxol hydrochloride in bulk and tablet dosage form, J. Pharm. Res. 4:1701-1703.

[17] A. K. Kovar and M. Abdel-Hamid, Arch. Pharm.,317 (1984) 246.

[18] Caulcutt, R. and Boddy, R. (1983). "Statistics for analytical Chemists" Chapman and Hall, London.

[19] http://www.rxlist.com/lexapro-drug.htm

[20] International Conference on Harmonization. (1995). ICH Harmonised Tripartite Guideline, Q2 (R1), Validation of Analytical Procedures: Text and Methodology, Switzerland. 